[Chem. Pharm. Bull.

36(10)4019-4025(1988)

\title{
Protection of Bovine Seryl-Transfer Ribonucleic Acid (Seryl-tRNA) Synthetase from Chemical Modification by Its Substrates, and Some Kinetic Parameters
}

\author{
Yoshio Tachibana and Takaharu Mizutani* \\ Faculty of Pharmaceutical Sciences, Nagoya City University, \\ Mizuho-ku, Nagoya 467, Japan
}

(Received April 20, 1988)

\begin{abstract}
Amino acid residues contained in the recognition sites of seryl-transfer ribonucleic acid (tRNA) synthetase (SerRS) were studied by chemical modification. Ser residues were modified with phenylmethanesulfonyl fluoride, and appeared to be unnecessary for the recognition. However, the modification of Arg residues with phenylglyoxal, His residues with diethylpyrocarbonate and sulfhydryl groups with 5,5'-dithiobis(2-nitrobenzoic acid), $\mathrm{N}$-ethylmaleimide, iodoacetic acid or iodoacetamide showed that these residues were essential for the tRNA recognition by SerRS. Protection experiments with substrates from inactivation of Ser-tRNA formation by modification suggested that Arg residues interact with the $\gamma$-phosphate of adenosine triphosphate and tRNA. Modification of sulfhydryl groups showed that the groups interact with the hydroxyl groups of ribose of the CCA-end on TRNA. Furthermore, in order to understand the recognition mechanism between SerRS and tRNA ${ }^{\text {Ser }}$, some kinetic parameters such as the $K_{\mathrm{m}}$ and $V_{\max }$ values of yeast tRNA $^{\text {Ser }}$ and $E$. coli tRNA $^{\text {Ser }}$ for bovine SerRS were compared with the values of bovine tRNA ${ }^{\text {Ser }}$.
\end{abstract}

Keywords_-Ser-tRNA synthetase; chemical modification; serine tRNA; sulfhydryl residues; recognition site; SerRS

\section{Introduction}

During the course of investigating the functions of serine transfer ribonucleic acid (tRNA) in higher vertebrates, we purified seryl-tRNA synthetase (SerRS) from bovine liver. ${ }^{1)}$ One kind of serine tRNA is a natural opal suppressor ${ }^{2}$ and is phosphorylated to phosphoseryl(Ps)-tRNA by tRNA kinase. ${ }^{3)}$ The incorporation of Ps into the read-through protein of $\beta$-globin was found. ${ }^{4}{ }^{4}$ The role of this tRNA is not clear. Ps-tRNA did not participate in phosphoserine aminotransferase catalysis or in the regulation of protein synthesis by competition for UGA with RF ${ }^{5,6)}$ Ps-tRNA should have a role in the synthesis of glutathione peroxidase, whose messenger ribonucleic acid (mRNA) contains the UGA codon for selenocysteine in the active site..$^{-10}$ )

The recognition mechanism between tRNA and aminoacyl-tRNA synthetase has not been fully elucidated. ${ }^{11.12}$ ) The crystallographic analysis of a complex of TyrRS and the substrates from Bacillus stearothermophilus was reported. ${ }^{13-15)}$ Eleven possible hydrogen bonds between TyrRS and tyrosyl adenylate were clarified. ${ }^{16,17)}$ Studies with some mutants of TyrRS indicated interactions between histidine residues of TyrRS and the substrates (Tyr, adenosine triphosphate (ATP) tRNA). ${ }^{18,19)}$ In the case of yeast, the possiblity of an interaction between tRNA ${ }^{\text {Asp }}$ and lysine residues of AspRS was reported. ${ }^{20)}$ The interaction between the 3'-end of tRNA and aminoacyl-tRNA synthetase was indicated on the peptide map ${ }^{21)}$ or by photo-crosslinking. ${ }^{22)}$ In this paper, we report the interaction between SerRS and the substrates (tRNA ${ }^{\text {Ser }}$, Ser or ATP) studied by chemical modification of SerRS, as well as some kinetic parameters of bovine SerRS for some serine tRNA species. 


\section{Materials and Methods}

Materials - $-\left[{ }^{14} \mathrm{C}\right]$ Serine was from the Commissariat a l'Energie Atomique and was used at the radio specific activity of $50 \mu \mathrm{Ci} / 2 \mu \mathrm{mol} / \mathrm{ml}$. Phenylmethanesulfonyl fluoride (PMSF) was purchased from Boehringer Mannheim GmbH, phenylglyoxal (PGO) and diethylpyrocarbonate (DEP) from Aldrich Chemical Co., 5'5-dithiobis(2nitrobenzoic acid) (DTNB), monoiodoacetic acid (MIA) and iodoacetamide (IAA) from Katayama Chemical Co., and $N$-ethylmaleimide (NEM) from Sigma Chemical Co.

Enzymes and tRNAs-Bovine liver SerRS ${ }^{1)}$ was purified as one band on sodium dodecyl sulfatepolyacrylamide gel electrophoresis (SDS-PAGE) through several purification steps according to a previous report. Assay of SerRS was also carried out according to the previous report, ${ }^{1}$ as follows. The standard assay mixture (45 $\left.\mu \mathrm{l}\right)$ for SerRS consisted of $0.2 \mathrm{M}$ Hepes (pH 7,6), $0.02 \mathrm{M} \mathrm{MgCl}, 0.02 \mathrm{M} \mathrm{KCl}, 5 \mathrm{~mm} \mathrm{ATP}, 40 \mu \mathrm{M}\left[{ }^{14} \mathrm{C}\right] \mathrm{Ser}(25 \mathrm{Ci} / \mathrm{mol})$ and $0.1 \mathrm{mg}$ of bovine tRNA. The mixture was preincubated at $37 \mathrm{C}$ and the reaction was started by adding $5 \mu \mathrm{l}$ of the enzyme solution. After incubation for $2 \mathrm{~min}$, the reaction mixtures were spotted on filter papers, which were then immersed in $10 \%$ trichloroacetic acid. The papers were then washed with $0.2 \mathrm{M} \mathrm{HCl}$ for $20 \mathrm{~min}$. The filters were dried and counted. The most effective buffer for the reaction of SerRS among Tris- $\mathrm{HCl}$, phosphate, cacodylate and Hepes buffers was the Hepes buffer, in which the velocity was $2-3$ times that inthe other buffers, This result coincides with a previous finding. ${ }^{23)}$ It is possible that amino residues on Tris and phosphate as buffers interact with some counter ions (phosphate residues and amino residues) on tRNA and SerRS, resulting in inhibition. The optimum pH of this reaction with bovine SerRS in 7.6 in Hepes buffer. SerRS in Bombyx mori was maximally active at $\mathrm{pH} 7.8{ }^{24)}$

Bovine tRNA ${ }_{1 G A}^{\text {Ser }}$ was purified by chromatography on BD-cellulose and on an RPC 5-like support. ${ }^{25)}$ Brewer's yeast serine tRNA was partially purified from crude tRNA purchased from Boehringer Mannheim GmbH. Escherichia coli serine tRNA was partially purified by chromatography ${ }^{26)}$ from crude tRNA.

Chemical Modification of Serine Residues on SerRS by PMSF — The supernatant of bovine liver extracts at $150000 \times \mathrm{g}$ in $0.25 \mathrm{M}$ sucrose, $10 \mathrm{mM} \beta$-mercaptoethanol, and $20 \mathrm{mM}$ Tris- $\mathrm{HCl}$ buffer in the presence or absence of PMSF $(35 \mathrm{mg} / \mathrm{ml})^{27)}$ was applied to a column $(60 \times 4 \mathrm{~cm})$ of Sephacryl S-300 in $10 \mathrm{mM} \mathrm{MgCl}_{2}, 10 \mathrm{mM} \beta$ mercaptoethanol, $10 \mathrm{~mm}$ Tris- $\mathrm{HCl}$ buffer $(\mathrm{pH} \mathrm{7.6)}$, and $5 \%$ glycerol, sometimes containing PMSF. The activity of SerRS in the eluate from the column was measured according to the procedure described above.

Chemical Modification of His Residues on SerRS by DEP__DEP was dissolved in ethanol at a concentration of $6.9 \mathrm{~mm}^{28)} \mathrm{DEP}(1 \mu \mathrm{l})$ was added to $100 \mu \mathrm{l}$ of $0.57 \mu \mathrm{M}$ SerRS solution. After incubation at $25^{\circ} \mathrm{C}$ for an appropriate time, a portion of the reaction mixture was used to measure the SerRS activity.

Chemical Modification of Arg Residues on SerRS by PGO_-Modification of SerRS was carried out accrding to an established procedure. ${ }^{29)}$ SerRS, at a concentration of $0.63 \mu \mathrm{M}$, was incubated with or without substrate (ATP or serine) in $50 \mathrm{~mm}$ sodium bicarbonate buffer, at pH 8.5, or substrate (tRNA) in $25 \mathrm{~mm}$ sodium bicarbonate-0.1 M Hepes buffer at $\mathrm{pH} 7.5$ for $10 \mathrm{~min}$ at $25^{\circ} \mathrm{C}$ before addition of PGO. After incubation, SerRS was modified with PGO at a concentration of $5 \mathrm{~mm}$ for $30 \mathrm{~min}$ at $25^{\circ} \mathrm{C}$. A part of the mixture was used to measure the SerRS activity.

Modification of Sulfhydryl Groups on SerRS by Sulfhydryl Reagents-The sulfhydryl reagents used in this study were DTNB $,^{30)} \mathrm{NEM},{ }^{30)}$ IAA, ${ }^{31)}$ and MIA. ${ }^{32)}$ The enzyme $(0.75 \mu \mathrm{M}$ in $0.2 \mathrm{M}$ Hepes at pH 7.5$)$ was incubated with the ligands for $3 \mathrm{~min}$ at $25^{\circ} \mathrm{C}$ before addition of the DTNB, NEM, or MIA. Modification of the enzyme with DTNB, NEM, or MIA was carried out for $5 \mathrm{~min}$ at $25^{\circ} \mathrm{C}$. In the case of IAA, SerRS was incubated with the ligands in $0.2 \mathrm{M}$ Hepes at $\mathrm{pH} 7.5$ for $3 \mathrm{~min}$ at $37^{\circ} \mathrm{C}$ and modification of the enzyme with $25 \mathrm{~mm}$ IAA was carried out for $30 \mathrm{~min}$ at $37^{\circ} \mathrm{C}$. After incubation, a part of the reaction mixture was used to measure SerRS activity.

Oxidation of tRNA with Periodate-Periodate oxidation of bovine $t R N A_{1 G A}^{\text {Ser }}$ was carried out by adding $0.25 \mathrm{ml}$ of $0.02 \mathrm{M} \mathrm{NaIO}_{4}$ to $20 \mathrm{~A}_{260}$ units of tRNA ${ }^{\mathrm{Ser}}$ in $1 \mathrm{ml}$ of $0.08 \mathrm{M}$ sodium acetate buffer at $\mathrm{pH} 5.0 .{ }^{33.34)}$ After incubation at $37 \mathrm{C}$ for $30 \mathrm{~min}$ in the dark, $0.3 \mathrm{ml}$ of $10 \%$ ethylene glycol was added and the incubation continued for an additional $10 \mathrm{~min}$. The mixture was precipitated with 2.5 volumes of ethanol and centrifuged. The precipitate was dissolved in $1 \mathrm{M}$ sodium acetate buffer, at $\mathrm{pH}$ 5.0, and precipitated once more with ethanol to remove excess reagent. The precipitate was washed with ethanol and ether and then dried. The oxidized tRNA was designated at tRNA Sx. $^{\text {Ser }}$ The remaining activity of tRNA $\mathrm{OX}_{\text {Ser }}^{\text {Ser }}$ was $2.9 \%$ of the initial activity.

\section{Results}

\section{Chemical Modification of Ser Residues on SerRS by PMSF}

Figure 1 shows the chromatographic patterns on a column of Sephacryl S-300 in the presence (lower column) or absence (upper column) of PMSF. The serine acceptor activity was eluted between standard ferritin $(460 \mathrm{kDa})$ and immunoglobulin $\mathrm{G}(\mathrm{IgG})(146 \mathrm{kDa})$, and gave an apparent molecular weight of $160 \mathrm{kDa}$ in both cases. This result shows that the aminoacylation was not inhibited by PMSF and that serine residues on SerRS did not participate in the reaction. SerRS was reported to be a dimer in the native state and to 

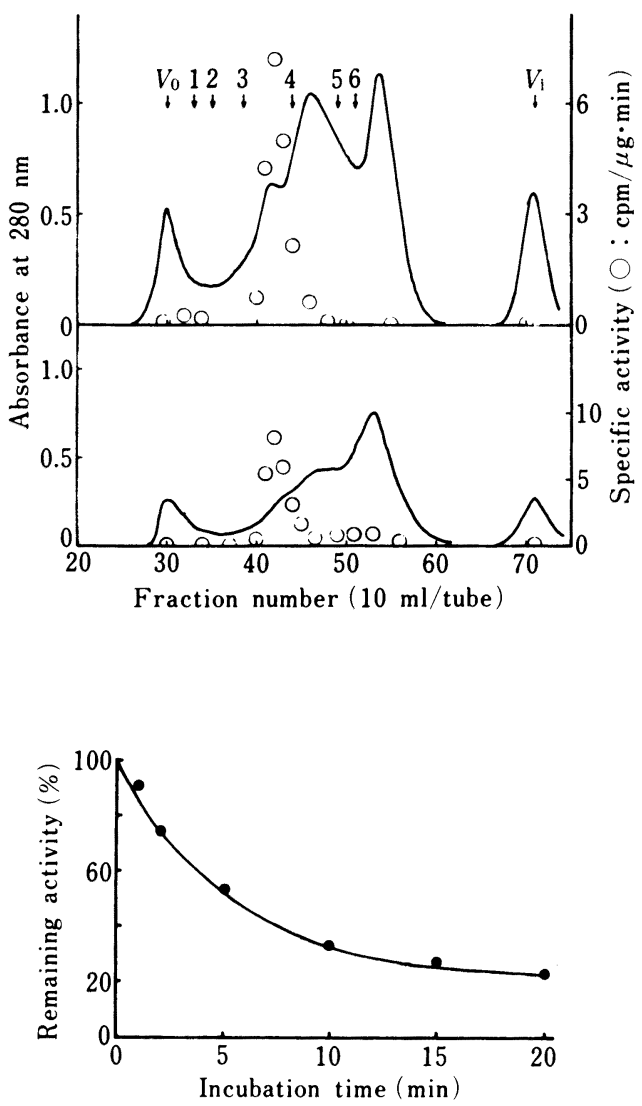

Fig. 2. Inactivation Pattern of SerRS Resulting from Modification of His Residues by DEP

Bovine liver SerRS was dissolved at $0.57 \mu \mathrm{M}$ and incubated at $25^{\circ} \mathrm{C}$ with $69 \mu \mathrm{M}$ DEP in $0.2 \mathrm{M}$ Hepes buffer, $\mathrm{pH} 7.5$, containing $0.02 \mathrm{M} \mathrm{KCl}$ and $0.02 \mathrm{M}$ $\mathrm{MgCl}_{2}$. Remaining activity of modified SerRS is shown as percent ratio (the activity of native SerRS was taken as $100 \%$ ).
Fig. 1. Chromatographic Patterns of SerRS on Sephacryl S-300 in the Absence (Upper) and in the Presence (Lower) of PMSF

PMSF ( $35 \mathrm{mg} / 2 \mathrm{ml}$ of 2-propanol/1 of buffer) was mixed with the supernatant obtained by centrifugation of bovine liver homogenates at $15000 \times g$. The mixture was chromatographed on a Sephacryl S-300 column. The assay conditions are described in the experimental procedure section. Open circles show the specific activity of protein in eluates. The activity indicates the incorporation of $\left[{ }^{14} \mathrm{C}\right] \mathrm{Ser}$ into bovine tRNA ${ }^{\text {Ser }}$ catalyzed by SerRS. Standard proteins are (1), IgM (900 kDa); (2), keyhole limpet hemocyanine (800 kDa); (3), ferritin (450 kDa); (4), IgG (146 kDa); (5), ovalbumin ( $46 \mathrm{kDa})$; and (6), peroxidase $(40$ $\mathrm{kDa}) . V_{\mathrm{o}}$ and $V_{\mathrm{i}}$ indicate the void volume and inner volume of the column.

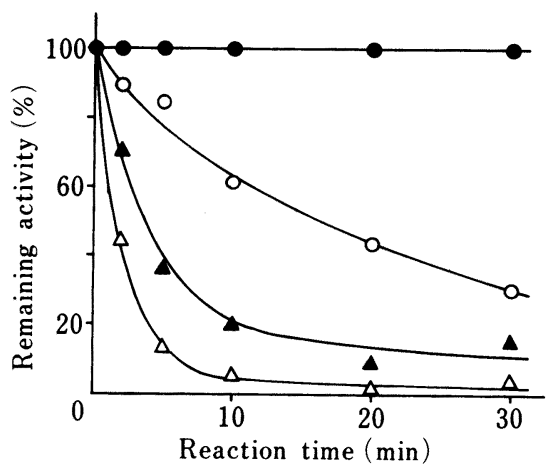

Fig. 3. Inactivation Pattern of SerRS Resulting from Modification of Arg Residues by PGO

SerRS was dissolved at $0.63 \mu \mathrm{M}$ and incubated at $23^{\circ} \mathrm{C}$ with PGO. The enzyme was incubated without (๑) or with $1 \mathrm{~mm}(\mathrm{O}), 2 \mathrm{~mm}(\boldsymbol{\Delta})$, or $5 \mathrm{~mm}(\triangle)$ PGO in $50 \mathrm{~mm}$ sodium bicarbonate buffer, $\mathrm{pH} 8.5$. The remaining activity of modified SerRS is shown, as in Fig. 2.

dissociate to the monomer of molecular mass $80 \mathrm{kDa}$ in SDS solution. ${ }^{1)}$ In Fig. 1, no activity was found at the position of the monomer. This result shows that either SerRS does not dissociate to the monomer in this solution, or the monomer of SerRS has no activity.

\section{Chemical Modification of His Residues by DEP and Arg Residues by PGO}

Figure 2 shows a plot of the remaining activity of SerRS, on which His residues were modified by DEP, against the reaction time. Since the activity was decreased to $30 \%$ after incubation for $10 \mathrm{~min}$, it was considered that His residues on SerRS wre related to the active sites.

Figure 3 shows the remaining activity of SerRS modified at Arg residues by PGO as a function of time. With increasing concentration of PGO, the inhibition of serine acceptor activity increased, with almost no activity after $30 \mathrm{~min}$ at $5 \mathrm{mM}$ PGO. Table I shows the protective effects of nucleotides, Ser, and tRNA against inactivation of SerRS by PGO. ATP, bovine tRNA ${ }^{\text {Ser }}$, tRNA $\mathrm{OX}$ provided good protection against inactivation. However, Ser, adenosine diphosphate (ADP), and Ser + ATP provided no protection against inactivation. AMP provided a slight protection. This different protection by ATP, ADP, and adenosine 
TABLE I. Protection of Bovine SerRS against Inactivation by $\mathrm{PGO}^{a}$

\begin{tabular}{clcc}
\hline \hline \multirow{2}{*}{ Experiment } & \multicolumn{1}{c}{ Ligand } & Concentration (mM) & Remaining activity (\%) \\
\hline \multirow{2}{*}{ A } & None & & 7 \\
& ATP & 5 & 10.4 \\
& ATP & 20 & 93.5 \\
& AMP & 20 & 51.6 \\
& ADP & 20 & 29.2 \\
& Serine & 0.05 & 35.9 \\
& Serine + ATP & $0.05+5$ & 30.3 \\
B & None & & 40.8 \\
& Bovine tRNA & & 100 \\
& Bovine tRNA & 0.0011 & 100 \\
\hline
\end{tabular}

a) SerRS at $0.63 \mu \mathrm{M}$ was incubated with the ligands in (A) $50 \mathrm{~mm}$ sodium bicarbonate buffer, $\mathrm{pH} 8.5$, or (B) $25 \mathrm{~mm}$ sodium bicarbonate buffer- $0.1 \mathrm{M}$ Hepes buffer, $\mathrm{pH} 7.5$, for $10 \mathrm{~min}$ at $23 \mathrm{C}$ before the addition of PGO. Incubation of the enzyme with $5 \mathrm{mM}$ PGO was carried out for $30 \mathrm{~min}$ at $23{ }^{\circ} \mathrm{C}$. $\mathrm{tRNA}$ Ser was obtained by treating the partially purified $\mathrm{tRNA} \mathrm{SGA}_{\mathrm{IGA}}^{\mathrm{Ser}}$ with periodate.

TABLE II. Summary of Chemical Modification of Bovine SerRS ${ }^{a}$

\begin{tabular}{|c|c|c|c|c|c|c|}
\hline \multirow{2}{*}{ Reagents } & \multirow{2}{*}{$\begin{array}{l}\text { Reactive } \\
\text { residues }\end{array}$} & \multirow{2}{*}{ Inactivation } & \multicolumn{4}{|c|}{ Protection of the residues by substrates ${ }^{b)}$} \\
\hline & & & Ser & ATP & $\operatorname{tRNA} A_{\mathrm{IGA}}^{\mathrm{Ser}}$ & tRNA $A_{O X}^{\text {Ser }}$ \\
\hline PMSF & Ser & - & $\mathrm{n}$ & $\mathrm{n}$ & $\mathrm{n}$ & $\mathrm{n}$ \\
\hline DEP & His & + & $\mathrm{n}$ & $\mathrm{n}$ & $\mathrm{n}$ & $\mathrm{n}$ \\
\hline $\mathrm{PGO}^{c)}$ & Arg & + & - & ++ & ++ & ++ \\
\hline $\mathrm{DTNB}^{d)}$ & $\mathrm{SH}$ & + & - & + & + & $\mathrm{n}$ \\
\hline NEM & SH & + & $\mathrm{n}$ & $\mathrm{n}$ & + & $\mathrm{n}$ \\
\hline MIA & SH & + & $\mathrm{n}$ & - & + & $\mathrm{n}$ \\
\hline IAA & SH & + & - & ++ & + & - \\
\hline
\end{tabular}

a) Enzyme was inactivated $(+)$ or not inactivated $(-)$ as shown in the third column. b) The inactivation by the reagent was almost completely prevented $(++, 90-100 \%$ inhibition), partially prevented $(+, 10-30 \%$ inhibition) or not prevented $(-)$ by the substrates as shown in the fourth column, and $\mathrm{n}$ is not determined. $c$ ) The results are shown in Table I. d) The results are shown in Fig. 4.

monophosphate (AMP) suggests that $\gamma$-phosphate residues on ATP interact with arginine residues on SerRS. The PGO results also suggest that $t R N A$ and $t R N A_{O X}^{\text {Ser }}$ may interact with arginine residues except for the $3^{\prime}-\mathrm{OH}$ residue on adenosine of tRNA.

\section{Modification of Sulfhydryl Groups of SerRS by DTNB, IAA and NEM}

SerRS remained active in the presence of $\beta$-mercaptoethanol and was inactivated by the removal of $\beta$-mercaptoethanol from the buffer, as was found for other aminoacyl-tRNA synthetases. ${ }^{11)}$ SerRS was inactivated by sulfhydryl reagents such as DTNB, NEM, MIA and IAA as shown in Table II. Therefore, sulfhydryl residues of SerRS were essential to preserve the activity. Figure 4 shows the protective effects of ATP, Ser, and bovine tRNA ${ }^{\text {Ser }}$ against inactivation of SerRS by DTNB. Serine provided no protection against inactivation by DTNB as shown in the left part of Fig. 4. However, $t R N A^{\text {Ser }}$ provided protection at $7.5 \mathrm{~mm}$ DTNB (the right part in Fig. 4), and ATP provided protection against inactivation by $5 \mathrm{~mm}$ DTNB (the middle column). Table II shows the protective effects of ATP, Ser, bovine tRNA $^{\text {Ser }}$, and tRNA OX $_{\text {Ser }}$ against inactivation of SerRS by IAA. ATP provided complete protection at $2 \mathrm{~mm}$, and even $0.1 \mathrm{~mm}$ ATP provided partial protection against inactivation. ATP at a concentration 50 -fold lower than the $K_{\mathrm{m}}$ value $(0.49 \mathrm{~mm})$ of ATP for SerRS, 


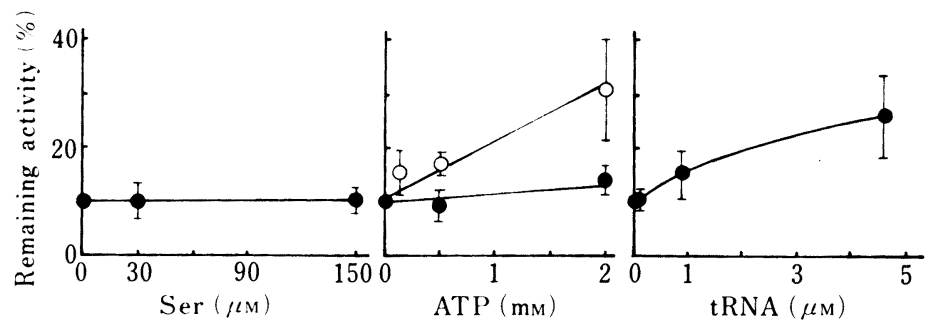

Fig. 4. Protection of the Sulfhydryl Groups of SerRS from DTNB Modification by Ser, ATP or Bovine tRNA ${ }^{\text {Ser }}$

The SerRS was incubated at $25 \mathrm{C}$ for $5 \mathrm{~min}$ with various amounts of Ser (left), ATP (center), or tRNA ${ }^{\text {sir }}$ (right). The assay conditions are described in the experimental procedure section. The bars show the S.E. of six experiments. Closed circles, 7.5 mM DTNB; open circles, $5 \mathrm{~mm}$ DTNB. Abscissae indicate the concentration of substrates for protection from modification.

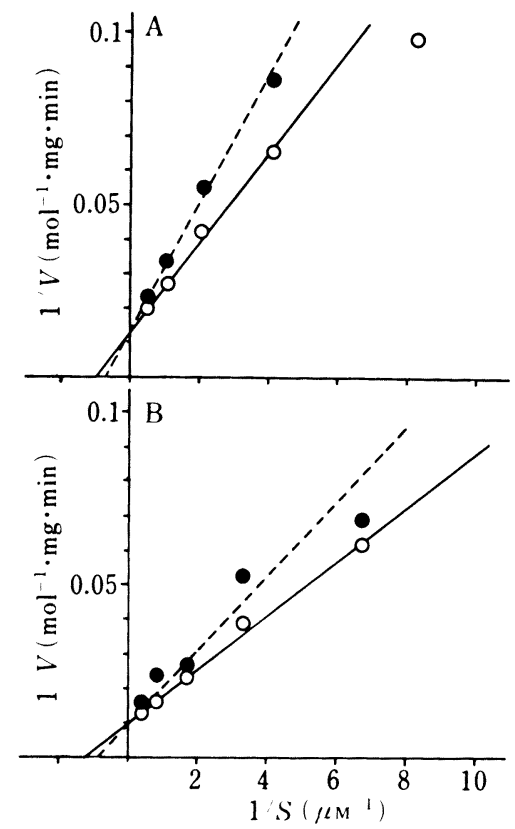

Fig. 5. Inhibition of the Aminoacylation of Bovine tRN $\Lambda_{\mathrm{IGA}}^{\mathrm{Ser}}$ by Bovine tRNA $\mathrm{OX}(\mathrm{A})$, and of Yeast tRNA $\mathrm{IGA}_{\mathrm{IGA}}^{\mathrm{Ser}}$ by Bovine tRNA $\mathrm{OX}_{\mathrm{OX}}^{\text {Ser }}(\mathrm{B})$

The concentration of $\mathrm{tRNA} \mathrm{AX}_{\mathrm{OX}}^{\mathrm{Ser}}$ was $0.2 \mu \mathrm{M}$. The assay conditions are described in the experimental procedures section. Open and closed circles show results in the absence and presence of $\mathrm{RNA}_{\mathrm{OX}}^{\mathrm{Ser}}$, respectively.

provided protection against inactivation (data not shown). Bovine tRNA ${ }^{\text {Ser }}$ also provided partial protection, but Ser and tRNA $\mathrm{OX}_{\mathrm{OX}}^{\mathrm{Ser}}$ provided no protection against inactivation. This result suggests that sulfhydryl groups on SerRS interact with the $\mathrm{OH}$ residues of adenosine in the 3 '-end of tRNA. Also, ATP may interact with sulfhydryl groups while Ser may not. Table II summarizes the results of the chemical modification, including MIA and NEM as well as the results with PMSF, DEP and PGO.

\section{Comparison of the Kinetic Parameters of Bovine Liver, E. coli and Yeast tRNAs ${ }^{\text {Ser }}$ for Bovine SerRS}

Bovine SerRS recognized three bovine $\mathrm{tRNA}^{\mathrm{Ser}}$ isoacceptors ${ }^{35}$ ) (tRNA $_{\mathrm{GCU}}^{\mathrm{Ser}}, \mathrm{tRNA} \mathrm{IGA}_{\mathrm{G}}^{\mathrm{Ser}}$, and $\mathrm{tRNA} \mathrm{CmCA}_{\mathrm{Cm}}^{\mathrm{Ser}}$ ) with the same $K_{\mathrm{m}}$ value and $V_{\max }$ value. However, the $K_{\mathrm{m}}$ values of bovine tRNA ${ }_{I G A}^{\text {Ser }}$, yeast tRNA $\mathrm{IGA}_{\mathrm{IGA}}^{\mathrm{Ser}}$, and $E$. colitRNA ${ }^{\text {Ser }}$ were $1.1,0.84$, and $20 \mu \mathrm{M}$, respectively, and the three $V_{\max }$ values were $83 \mathrm{nmol} / \mathrm{mg} / \mathrm{min}, 105 \mathrm{nmol} / \mathrm{mg} / \mathrm{min}$ and $3.9 \mathrm{nmol} / \mathrm{mg} / \mathrm{min}$, respectively. The affinity of $E$. coli $\mathrm{tRNA}{ }^{\text {Ser }}$ for bovine SerRS was about one-twentieth of that in the bovine homologous system and the velocity was one-twenty-fifth. From these results, we 
considered that $E$. coli $\mathrm{tRNA}^{\mathrm{Ser}}$ was not recognized as a good substrate for SerRS. Meanwhile, yeast tRNA $\mathrm{IGA}_{\mathrm{IGA}}^{\mathrm{Ser}}$ was a good substrate, as was bovine tRNA $\mathrm{IGA}_{\mathrm{IGA}}^{\text {Ser }}$ Figure 5 shows Lineweaver-Burk plots of the inhibition of the aminoacylation of bovine $T R \mathrm{RA}_{\mathrm{IGA}}^{\mathrm{Ser}}$ or of yeast tRNA ${ }_{\text {IGA }}^{\text {Ser }}$ by bovine tRNA ${ }_{\mathrm{OX}}^{\text {Ser }}$, which was a derivative of bovine liver tRNA $\mathrm{IGA}_{\mathrm{IGA}}^{\mathrm{Ser}}$. In both cases, the inhibition was competitive. Therefore, some sites involved in the recognition mechanisms of the two tRNAs seem to be common.

\section{Discussion}

We studied whether bovine liver SerRS recognized yeast or $E$. coli $\mathrm{tRNA}{ }^{\text {Ser }}$. Yeast tRNA ${ }^{\text {Ser }}$ was recognized, but $E$. coli tRNA was not. The homologies of the mammalian, yeast, and $E$. coli tRNA $^{\text {Ser }}$ sequences ${ }^{35)}$ were found. The $E$. coli $\mathrm{tRNA}{ }^{\text {Ser }}$ differences were at only a few positions (anticodon stem, variable loop, and $\mathrm{T} \psi$ stem). It is proposed that tRNAs interact with synthetases through the inside of the two branches forming the L-shaped tRNA molecule. ${ }^{11.12)}$ On the other hand, the anticodons of three bovine tRNAs ${ }^{\text {Ser }}$ (tRNA $_{\text {IGA }}^{\text {Ser }}$, tRNA ${ }_{G C U}^{\mathrm{Ser}}$ and tRNA $\mathrm{CmCA}_{\mathrm{Cm}}^{\mathrm{Ser}}$ ) are clearly different so the anticodon of $t \mathrm{RNA}^{\mathrm{Ser}}$ is not involved in the recognition site. Similar sequences among tRNAs ${ }^{\text {Ser }}$ were present in the D loop, the D stem, the anticodon stem, the T $\psi$ loop, and $\mathrm{T} \psi$ stem. These positions may be involved in the recognition sites. tRNA ${ }_{\text {OX }}^{\text {Ser }}$ inhibited the aminoacylation of bovine liver or yeast tRNA ${ }^{\text {Ser }}$ competitively. This result shows that $\mathrm{TRNA} \mathrm{OX}_{\mathrm{OX}}^{\mathrm{Ser}}$, oxidized at the $3^{\prime}$-end, inhibits the binding between tRNA ${ }^{\text {Ser }}$ and SerRS.

The results on protection by various ligands from chemical modification may be summarized as follows. Since the serine acceptor activity was unchanged by PMSF, it was concluded that Ser residues were not related to the active sites. Meanwhile, SerRS was inactivated by DEP, so it seemed that His residues are involved in the active sites. It is known from the crystal structure of the enzyme-bound tyrosyl-adenylate that a His at position 48 is in close proximity to the ribose ring oxygen of ATP and there is a hydrogen bond between $\pi$ $\mathrm{N}$ of His and ATP. ${ }^{18)}$ It has also been found that the $\gamma$-phosphate groups of ATP is hydrogenbonded with the side chain of Thr-40 and His-45. ${ }^{19)}$

Since SerRS was inactivated by PGO, Arg residues must be related to the active site. From the results on the protective effects of ATP, ADP, or AMP, it was considered that Arg residues played an important role as a binding site for the $;$-phosphate group of ATP in the transition state and for pyrophosphate in the reverse reaction. The results on the protective effect of tRNA or tRNA ${ }_{\text {OX }}^{\text {Ser }}$, showed that Arg residues interacted with tRNA, but that the adenosine of the CCA-end was not involved in the interaction.

SerRS was inactivated by sulfhydryl reagent, and this result showed that sulfhydryl groups were related to the active sites. The difference between the results with different sulfhydryl reagents was considered to reflect the reactivity of the reagents or the positions of the modified sulfhydryl groups. As shown in Table II, the complete protection by ATP indicates that ATP interacted with sulfhydryl group. It was reported that the thiol-containing side chain of Cys-35 of TysRS formed a hydrogen bond with the 3'-OH of the ribose of ATP. ${ }^{16,17)}$

In order to study in detail the interaction between SerRS and substrates, it will be necessary to investigate the protective effects of ligands in the ATP-PPi exchange reaction. It must also be ascertained that the inactivation by these reagents does not depend upon conformational changes of SerRS but is due to modification of residues at the active sites of SerRS. 
2) D. Hatfield, Tends Biochem. Sci., 10, 201 (1985).

3) T. Mizutani and A. Hashimoto, FEBS Lett., 169, 319 (1984).

4) T. Mizutani and Y. Tachibana, FEBS Lett., 207, 162 (1986).

5) T. Mizutani, K. Kanbe, Y. Kimura, Y. Tachibana, and T. Hitaka, Chem. Pharm. Bull., 36, 824 (1988).

6) T. Mizutani and T. Hitaka, FEBS Lett., 216, 217 (1988).

7) Y. Sukenaga, K. Ishida, T. Takeda, and K. Takagi, Nucleic Acids Res., 15, 7178 (1987).

8) I. Chambers, J. Frampton, P. Goldfarb, N. Affara, W. McBain, and P. R. Harrison, EMBO J., 5, 1221 (1986).

9) R. A. Sunde and J. K. Evenson, J. Biol. Chem., 262, 933 (1987).

10) T. Mizutani and T. Hitaka, FEBS Lett., 232, 243 (1988).

11) P. R. Schimmel and D. Söll, Ann. Rev. Biochem., 48, 601 (1979).

12) P. R. Schimmel, Ann. Rev. Biochem., 56, 125 (1987).

13) C. Montelhet and D. M. Blow, J. Mol. Biol., 122, 407 (1978).

14) J. Rubin and D. M. Blow, J. Mol. Biol., 145, 489 (1981).

15) T. N. Bhat, D. M. Blow, P. Brick, and J. Nyborg, J. Mol. Biol., 158, 699 (1982).

16) A. R. Fershet, J. P. Shi, J. Knill-Jones, D. M. Lowe, A. J. Wilkinson, D. M. Blow, P. Brick, P. Carter, M. Y. Waye, and G. Winter, Nature (London), 314, 235 (1985).

17) T. N. C. Wells and A. R. Fershet, Nature (London), 316, 656 (1985).

18) D. M. Lowe, A. R. Fershet, A. J. Wilkinson, P. Carter, and G. Winter, Biochemistry, 24, 5106 (1985).

19) R. J. Leatherbarrown, A. R. Fershet, and G. Winter, Proc. Natl. Acad. Sci. U.S.A., 82, 7840 (1985).

20) D. Kern, B. Lorber, Y. Boulanger, and R. Giege, Biochemistry, 24, 1321 (1985).

21) C. Hountondji, S. Blanquet, and F. Lederer, Biochemistry, 24, 1175 (1985).

22) E. J. Ackerman, A. Joachmiak, V. Klinghofer, and P. B. Sigler, J. Mol. Biol., 181, 93 (1985).

23) H. Jakubouski and J. Pawelkiewicz, Eur. J. Biochem., 52, 301 (1975).

24) S. Viswanathan and J. D. Dignam, J. Biol. Chem., 263, 535 (1988).

26) T. Mizutani and Y. Tachibana, J. Chromatogr., 324, 480 (1985).

27) E. J. Walker, G. B. Treacy, and P. D. Jeffery, Biochemistry, 22, 1934 (1983).

28) C. H. Soon, G. M. Shepherd, and P. A. Sullivan, Biochem. J., 165, 385 (1977).

29) M. Kanda, K. Hori, S. Miura, Y. Yamada, and Y. Saito, J. Biochem. (Tokyo), 92, 1951 (1982).

30) M. Kanda, K. Hori, T. Kurotsu, S. Miura, and Y. Saito, J. Biochem. (Tokyo), 96, 701 (1984).

31) M. Kawamura, P. S. Keim, Y. Goto, H. Zalkin, and P. L. Heinrikson, J. Biol. Chem., 253, 4659 (1978).

32) G. W. Robinson, R. A. Bradshaw, L. Kaharek, and R. L. Hill, J. Biol. Chem., 242, 2709 (1967).

22) J. Torres-Gallardo and M. Kern, Proc. Natl. Acad. Sci. U.S.A., 53, 91 (1965).

34) Y. Furuichi and K. Miura, J. Mol. Biol., 64, 619 (1972).

35) M. Sprinzl, J. Moll, F. Messner, and T. Hartmann, Nucleic Acids Res., 13, r1-r49 (1985). 